\title{
LIST OF MAPS AND DIAGRAMS
}

FIGURE

1 Principal Human Breeds and Blends of the Mediterranean and Adjacent Regions......................................... 31

2 Comparative Table of Cephalic Indices............................ 58

3 Geographical Distribution of Greek Dialects in Early Classical Times........................................................... 84

4 Geographical Distribution of Pre-Hellenic Peoples and Survivals of Them in Greek Folk-Memory................. 93

5 The Greater Powers of the Near East, 1500-1200 B.C.... 114

6 Principal Movements of Peoples in the Near East, 20001150 B.C.

7 Probable Distribution of Greek Dialects in the Thirteenth and Twelfth Centuries B.C

8 Diagram to Illustrate the Logic of Date-marks.

9 Principal Cultures of the Near East, Mediterranean and Peninsular Europe, at the Beginning of the Bronze Age.

10 Principal Non-Minoan Cultures and Non-Minoan Elements in the South Ægean............................................ 258

11 Geographical Distribution of Minoan Sites...................... 275

12 Geographical Distribution of Certain Peoples in the Fourteenth and Thirteenth Centuries B.C. inferred from Greek Folk-Memory.

13 Selected Genealogies Preserved in Greek Folk-Memory from Pre-Dorian Times 344,345

14 Types of Fibulae from Greece and the Ægean 406-7

15 Geographical Distribution of the Principal Types of Fibulae in Greece, the Ægean, and the Near East..... 415

16 The "Concentric Circle" Ornament .................................. 452

17 Examples of Wheel-made Rhythmical Decoration............ 470

18 Examples of Counterchanged Design................................ 497

19 Metrical and Geometrical Rhythms Compared................ 512

20 Rhythmical Panel Composition with Pictorial Content... 513

21 Design on the Shield of Achilles. Iliad XVIII. 430-606.. 519 